\title{
AVENTURA, AMOR Y DESEO EN LOS RELATOS DE VIAJE: WILLIAM HENRY HUDSON Y LUCIO V. MANSILLA
}

\author{
POR \\ LeILA GómeZ \\ University of Colorado at Boulder
}

La crítica de la literatura de viajes ha atendido al erotismo constitutivo de las relaciones que el viajero mantiene con los habitantes de los lugares visitados o explorados. En especial las narraciones de viajeros imperiales o neo-imperiales decimonónicos han sido analizadas en lo que refiere al deseo sexual insertas las dinámicas del poder físico y simbólico del colonizador-colonizado, ya desde el clásico Orientalism (1978) de Edward Said y, pasando por Imperial Eyes (1992) de Mary Louise Pratt, The Rhetoric of Empire (1992) de David Spurr y Colonial Desire (1995) de Robert Young, entre otros estudios representativos. En este trabajo me propongo leer aspectos del erotismo en dos relatos de viajes, los que comparten además el hecho de ser narraciones sobre el imperio y su misión civilizatoria, la guerra, la constitución de la nación moderna y el papel clave de las mujeres en el proyecto nacional/imperial del viajero. Me refiero a The Purple Land (1885) de William Henry Hudson y Una excursión a los indios ranqueles (1870) de Lucio V. Mansilla. Sostengo que el modo que las relaciones amorosas asumen entre el viajero y las mujeres locales predica sobre las maneras en que el proyecto de nación (argentina) en el caso de Mansilla y el imperio (inglés) en el caso de Hudson es visualizado, idealizado y en ocasiones parodiado por ambos viajeros.

Los encuentros eróticos se entienden de este modo como (potenciales) prácticas re-territorializadoras (Deleuze y Guatari, Anti-Oedipus), a partir de presentarse como alianzas sexuales y afectivas que asegurarían o desbaratarían vínculos políticos, sociales y económicos. En Foundational Fictions, Doris Sommer ha estudiado los romances nacionales decimonónicos en clave alegórica lo que en principio parece ser lo que aquí sostengo aunque aplicado al relato de viajeros. La autora argumenta que las alianzas amorosas son alegorías de la unión -de otro modo conflictiva- entre grupos raciales, sociales y económicos en la nación moderna latinoamericana. Aunque coincido con esta lectura para el caso de novelas como Amalia, Sab y otras tratadas en Foundational Fictions, en las que la nación aparece no sólo pensada o imaginada sino también querida y deseada por sus ciudadanos. En mi lectura de The Purple Land y Una excursión a los indios ranqueles las alianzas sexuales, todas queridas más o menos veladamente pero 
todas indefectiblemente frustradas, no son planteadas en clave alegórica en cuanto a su significación para la unión nacional, sino que efectivamente el encuentro erótico y la unión afectiva involucran indiscutidamente alianzas políticas o su amenaza. El melodrama y el sentimentalismo adquieren en las narraciones de Hudson y Mansilla vínculos explícitos con la política nacional y las relaciones coloniales de los viajeros.

Tanto The Purple Land como Una excursión a los indios ranqueles son relatos de la guerra y las disputas acerca de la consolidación del proyecto modernizador sobre el territorio nacional. Sin embargo, a pesar de ser la guerra o su prevención el motivo del viaje (aunque en Hudson esto sucede más adelante en el relato y no en su origen), son las relaciones de románticas y de camaradería las que tejen la trama de la aventura. El viajero de The Purple Land, Richard Lamb, llega a la Banda Oriental huyendo de un padre argentino celoso al haberse Lamb casado con su hija. La razón para el rechazo de Lamb por parte del padre es justamente su extranjería, el ser inglés, aun a pesar de haber vivido varios años en el Río de la Plata. En Montevideo, Lamb comienza a buscar trabajo para mantener a su flamante esposa. Su condición de extranjero vuelve difícil su inserción laboral sobre todo en un país que atraviesa por una situación bélica (entre Blancos y Colorados). Así comienzan las aventuras del viajero Lamb por territorio uruguayo, las que entrelazarán anécdotas de guerra con episodios amorosos.

En Una excursión a los indios ranqueles, el coronel Lucio V. Mansilla viaja a la zona de los indígenas al sur de Córdoba y la Pampa argentina, para afianzar un tratado de paz entre el gobierno nacional y los ranqueles, tratado que, en caso de resistencia por parte de los indígenas, será motivo de guerra. Aunque la amenaza y el peligro son constantes, Mansilla prefiere narrar historias de intrigas entre hombres y mujeres. Una de estas mujeres, su comadre mestiza Carmen, se presentará como el objeto velado de su deseo.

Ambos relatos son así relatos de viaje y aventura, esta última en su doble acepción tanto de empresa de resultado incierto que presenta riesgos, como en su definición de relación amorosa ocasional (RAE). La aventura entendida en su acepción sentimental, la que en muchos casos involucra transgresión de la legitimidad conyugal, también presenta riesgos para los viajeros, siendo el principal de ellos el mestizaje de los hijos, tema principal en los discursos racialistas imperiales y nacionales del siglo XIX.

Sin lugar a discusión, ambos relatos hacen un mapa de los territorios explorados. Gracias a su comadre Carmen, a los cautivos y rehenes cristianos y otros intermediarios de la frontera, Mansilla brinda datos demográficos, físicos y antropológicos que servirán al ojo legislador del Estado y su maquinaria militar e invasora. Hudson, no obstante, hace un mapa más claramente erótico de la Banda Oriental, más en el estilo de Richard Burton en su viaje al Oriente. Cada hito de terreno está marcado por un encuentro amoroso y una mujer que le indicará rutas identitarias a explorar. 
Existe en la literatura de viajes el estereotipo del viajero científico infantilizado y andrógino que no repara en las opciones amorosas de su alrededor en los lugares visitados. Mary Louise Pratt ha estudiado este estereotipo en los viajeros europeos a África y lo ha explicado como una figura de la anticonquista, es decir como un agente del imperio que busca, a través de la infantilización, afirmar el discurso del desinterés científico y por tanto su distancia con respecto a prácticas coercitivas del imperio en lo que respecta a lo político, económico y militar. Aunque sabemos que las expediciones científicas en la mayoría de los casos acompañaron la expansión imperial, en sus relatos, el científico se presentaría como solamente interesado en el descubrimiento y estudio de la naturaleza por ella misma, asegurando así su inocencia en lo que refiere a las prácticas de expansivas y militares.

Al respecto, Pratt estudia, entre otros, al viajero sueco Anders Sparrman, discípulo de Líneo, mandado a África en 1772. Sparrman se uniría a la segunda expedición de Cook alrededor del mundo, quedándose en el Cabo de Buena Esperanza hasta 1776. $\mathrm{Su}$ relato es considerado el primero en plasmar una experiencia personal detallada del interior del sur africano y es uno de los más citados. El Voyage to the Cape of Good Hope fue publicado primero en sueco en 1783, su traducción alemana fue publicada en 1784, cuatro ediciones en inglés le siguieron en 1785 y las traducciones al holandés y al francés aparecieron en 1789 (Pratt 50). Me interesa recalcar aquí la configuración del viajero naturalista en el relato de Sparrman y que Pratt analiza como una estrategia de la anticonquista, principalmente porque en The Purple Land, el naturalista Lamb parodia este modelo, produciendo significados diferentes sobre las relaciones imperiales. Dice Pratt al respecto de Voyage to the Cape of Good Hope:

On a particularly fruitful day of collecting, Sparrman finds his insect box is full, and he is "obliged to put a whole regiment of flies and other insects round the brim of [his] hat." In search of a place to stay, he is directed to the house of "a rich and infirm widow of fifty two years of age." On arriving, Sparrman attempts to conceal his bugfestooned hat in order not to alarm his hostess. He is betrayed at dinner, however, by the servants, one of whom whispers to her mistress that his hat "was full of little beasts (kleine bestjes)". (55)

Pratt explica que esta ridiculización del viajero forma parte de un conjunto de estrategias para distanciarse de la tensión amorosa que se genera en la casa de la viuda, donde el joven naturalista comenta principalmente sobre la madurez de la mujer, deserotizándola, sobre todo por su incapacidad (la de la viuda y sus amigos) para entender el lenguaje de la historia natural, lenguaje que Sparrman empleaba para hablar de su colección y el que provocaba la risa de sus interlocutores: "when he does

Revista Iberoamericana, Vol. LXXXII, Núm. 257, Octubre-Diciembre 2016, 703-719 ISSN 0034-9631 (Impreso)

ISSN 2154-4794 (Electrónico) 
appear, the self-effacing protagonist of the anti-conquest is often surrounded by an aura not of authority, but of innocence and vulnerability" (56).

En la historia de Hudson, como dijimos, se parodia este modelo del viajero naturalista. ${ }^{1}$ En su trayecto, Lamb se encuentra con uno de los líderes del bando revolucionario de los Blancos, Marcos Marcó, y junto a él es tomado prisionero por los agentes del gobierno y llevado hasta la casa del juez, para que éste determine la penalidad que estos vagabundos debían sufrir. Ante la apelación de Lamb a su nacionalidad inglesa, el juez concede que el viajero no sea encarcelado, sino solo Marcos Marcó (a quien no se reconoce todavía como un líder sino solo como un gaucho más). Al observar Marcos Marcó que la mujer del juez se inclina favorablemente hacia Lamb, le pide que lo ayude a conseguir de ella la llave del cepo con el que será encarcelado para de esta manera sólo aliviar la incomodidad durante la noche. Lamb lo hace, hallando que al día siguiente Marcos Marcó se ha fugado, dejándolo con un favor que pagar a la mujer, por la que siente gran repugnancia. En este capítulo titulado "La mujer y la serpiente" claramente haciendo alusiones a la tentación y al pecado, Lamb es presentado conforme a las características de la infantilización y auto-ridiculización del viajero naturalista, con el objetivo explícito de ahuyentar a la viuda.

Sin embargo, apenas me hube sentado cuando encontré que debía enfrentar una desagradable consecuencia de mi acción: el derecho de la obesa señora, que reclamaba mi imperecedera devoción y gratitud. La dama saludó mi entrada con efusiva sonrisa; y las sonrisas más dulces de algunas personas con que uno se topa son menos soportables que sus más perversas miradas. Para defenderme adopté la mayor expresión de sueño y estupidez que pude, para contrarrestar la de mi fisonomía natural, casi demasiado franca. Fingí no oír o entender mal todo lo que se me decía; al fin me sentí tan soñoliento que varias veces estuve a punto de caerme de la silla; en cada oportunidad, después de exagerados cabeceos, me enderezaba y miraba con ojos vacíos a mi alrededor... (95-6) ${ }^{2}$

Inventando excusas intenta alejarse de la señora, a la que rechaza por su edad y por su aspecto físico, no por ser una mujer casada ni mucho menos por ser la mujer del juez que va a decidir su destino en la Banda Oriental. Sin embargo, la mujer lo sigue en una de sus caminatas y en medio de sus insinuaciones descubre una pequeña víbora que la asusta. Al percatarse Lamb de que la víbora mantendría lejos a la mujer,

1 Como se sabe, además de sus obras de ficción, Hudson (1841-1922) escribió sobre historia natural, principalmente del Río de la Plata, lugar en el que nació y vivió hasta los treinta y tres años. Entre sus escritos de naturalista se encuentran las cartas publicadas en las Proceedings of the Zoological Society, Argentine Ornithology: A Descriptive Catalogue of Birds of the Argentine Republic, con P. L. Scatler (1888-9), The Naturalist in La Plata (1892), The Book of Naturalist (1919) y Birds of La Plata (1920).

2 En adelante todas las citas corresponden a la traducción al castellano de The Purple Land citada en la bibliografía.

Revista Iberoamericana, Vol. LXXXII, Núm. 257, Octubre-Diciembre 2016, 703-719 ISSN 0034-9631 (Impreso)

ISSN 2154-4794 (Electrónico) 
la recoge y comienza a hablarle a la señora de las propiedades físicas de la culebra: "Vea el brillo de sus ojos, que parecen dos diamantitos... véalos de cerca, señora, que bien merecen su admiración" (100), con el objetivo de asustarla y fastidiarla aún más. La mujer retorna con rabia a la casa y Lamb decide conservar a la culebra como talismán para protegerse de las "desagradables atenciones de la dama" y la pone nada menos que en su sombrero, como lo había hecho también Sparrman. Al igual que en el Voyage, cuando el naturalista regresa a la casa, la víbora se escapa:

Me hallaba en la cocina refrescándome con un cimarrón, cuando la dueña de casa entró radiante de sonrisas, pues al parecer me había perdonado. Me levanté cortésmente y me quité el sombrero. Desgraciadamente me había olvidado de la culebra, la que al descubrirme cayó al suelo; aquello dio lugar a gritos, confusión y a que la señora, los chicos y las sirvientas salieran a la carrera de la cocina. (100)

Los paralelismos con el relato de Sparrman son más que evidentes señalando una indiscutida intertextualidad entre ambos. Hudson reinscribe así a su viajero en el modelo de la literatura de viaje y el estereotipo del naturalista y el erotismo, aunque al hacerlo, lo parodia resaltando que la mujer no le resultaba físicamente atractiva. Contrasta su actitud en este capítulo con la fuerte inclinación de Lamb a involucrarse afectivamente con todas las mujeres, o casi todas, que encuentra en su periplo. La no admisión de que prefería mantenerse lejos de la mujer porque era justamente la esposa del juez que decidiría su castigo lo obliga a culpabilizarla a ella del desencuentro erótico, cuando en realidad es muy plausible que primara en su rechazo el miedo por su vida y el respeto por la autoridad. Lo interesante es el despliegue consciente del modelo del naturalista infantilizado y andrógino como estrategia de distancia y rechazo al encuentro erótico, a diferencia de la actitud de distanciamiento "inconsciente" o más sutil de Sparrman con la viuda en África. En el encuentro con esta mujer uruguaya, Lamb desmonta el sistema de convicciones de la "anti-conquista" del viajero, mostrando sus intereses abiertamente y el uso de la historia natural como subterfugio en materia política, legal y sentimental.

El lenguaje del naturalista aparece desenmascarado en otras ocasiones, también cuando es usado para ocultar intenciones eróticas. Una de ellas es el episodio de la bella Margarita, una niña de catorce años que ha despertado el vivo interés de Lamb por su belleza y originalidad "racial" en la Banda Oriental. Para Lamb, es un enigma la blancura de la piel de Margarita, el color azul de sus ojos y sus cabellos dorados en un hogar campesino y de padres mestizos, "[...] mostrando bien a las claras que por sus venas corría más de una gota de sangre charrúa" (64). Margarita ejerce gran fascinación en el viajero, pero Marcos Marcó, el padrino de la niña, lo amenaza para impedir cualquier avance amoroso. De nuevo, el lenguaje del naturalista se usa como subterfugio de la confesión de deseo sexual. Hablando de Margarita en un sentido

Revista Iberoamericana, Vol. LXXXII, Núm. 257, Octubre-Diciembre 2016, 703-719 ISSN 0034-9631 (Impreso)

ISSN 2154-4794 (Electrónico) 
ambiguo refiriéndose tanto a la niña como a la flor, Lamb prefiere evadir el tema de su gusto por la niña y concentrarse específicamente en las características de la naturaleza, llegando incluso a practicar la disección, en frente de Marcos Marcó, de una margarita, y mostrarle así la estructura por medio de la cual la flor se fecunda a sí misma. Al exponer las partes internas de la flor, Lamb explica "[...] con palabras sencillas los principios en que se funda la clasificación de las plantas, hablándole de esa linguna [sic] franca por medio de la cual todos los botánicos del mundo podrían entenderse y hablar de las plantas" (81). Lamb insiste en la universalidad y desinterés de su trabajo al recalcar, haciendo clara alusión a la niña también en este caso, que "[...] yo soy un botánico, un hombre que estudia las plantas y por eso todas son igualmente interesantes para mí" (81). Lo curioso es que Marcos Marcó, luego de escucharlo atentamente responde sarcásticamente, poniendo en tela de juicio el sistema de saberes establecidos y canonizados del naturalista:

Escuchaba maravillado, agotando todo su repertorio a expresiones tales como: “¡Dios mío! ¡Qué extraordinario! ¡No me diga!’ Terminé mi disertación convencido de que mi inteligencia superior había desconcertado a ese ignorante; luego, arrojando a un lado los restos de la flor que había sacrificado, volvía a guardar el cortaplumas en mi bolsillo. -Esas cosas, señor, las oímos pocas veces en la Banda Oriental-dijo-. Pero los ingleses saben todo... hasta los secretos de una flor. Pueden hacer casi cualquier cosa. Dígame señor botánico, ¿ha tomado parte alguna vez en la representación de una comedia? (81)

En este pasaje, el lenguaje de la ciencia se descubre como escamoteo a la proliferación de deseos y sentimientos, sobre todo en situaciones asimétricas de poder entre el viajero y las colonias, revelando la perspicacia de los nativos para interpretar las ocultas intenciones de los extranjeros hacia sus mujeres y niñas.

El último episodio que me gustaría analizar en este apartado es el que tiene como protagonista a Dolores, criolla del bando de los Blancos y seguidora incondicional de Santa Coloma (el líder de los Blancos, antes conocido en el relato como Marcos Marcó). En este episodio, la pasión invade a ambos personajes, al punto de que Lamb olvida que está casado con Paquita y cede al impulso de besar a Dolores, confesando su amor por esta última aunque no su matrimonio con la argentina. Lamb le había ofrecido cambiar sus servicios militares a la causa de los Blancos, es decir pelear en la guerra, a cambio de un beso de Dolores. Al aceptar el pacto, Dolores se entrega a Lamb y éste parte al día siguiente para unirse a las tropas de Santa Coloma. Más allá de los arrepentimientos y confesiones posteriores entre ambos, como la de Lamb acerca de Paquita, el acontecimiento marca el cruce de los sentimientos y la política y las inextricables alianzas.

La crítica ha debatido, desde la famosa lectura de Borges sobre el desinglesamiento de Lamb en The Purple Land (Gómez; Gómez y Castro-Klarén), si efectivamente en el

Revista Iberoamericana, Vol. LXXXII, Núm. 257, Octubre-Diciembre 2016, 703-719 ISSN 0034-9631 (Impreso) 
personaje se opera una suerte de pasaje de la identidad inglesa a la gaucha o rioplatense. Si bien es cierto que esto se da en algunos aspectos más que en otros, es indiscutible que es el amor de una mujer el que genera el pasaje al ejército cimarrón, el que sitúa al personaje en un cambio de nacionalidad y moralidad. Lamb pelea en el ejército de los Blancos y se involucra en el destino militar y político de la Banda Oriental por el beso de una mujer. La batalla en la que Lamb pelea no tiene mayores consecuencias y el narrador mismo se niega a ahondar en los detalles de la escaramuza, y nunca vuelve a ver a Dolores. No obstante, Lamb ha cambiado radicalmente, a partir de entonces mata a un hombre, se involucra en relaciones sexuales posteriores y decide radicarse para siempre en la Banda Oriental después de la muerte de su esposa. El amor y el deseo juegan un papel preponderante en la constitución identitaria del protagonista.

Si hasta el momento el nomadismo había sido la marca del itinerante Lamb, son el beso de Dolores y su primera incursión física en la guerra de los uruguayos los móviles que originan el afincamiento del viajero en el país, es decir, su "re-territorialización" en palabras de Deleuze y Guattari. Para los autores, el nomadismo puede interpretarse como una forma lateral de resistencia al control hegemónico del Estado sobre el espacio, al permitir múltiples e inestables recorridos sin objetivo de fijación o radicación. En este sentido, el viajero Lamb resiste al mandato de "establecerse" en un lugar determinado gracias al cual la burocracia estatal y las instituciones de la sociedad civil que la garantizan -como la familia- se permiten mapear y fijar el territorio de la nación. Hasta el momento nómade, Lamb describe un movimiento constante de desterritorialización, el que no es planeado por él, sino más bien promovido por la guerra y el deslizamiento de las tropas revolucionarias de los Blancos contra los Colorados, estos últimos representantes del gobierno establecido en la República. Sin embargo, el beso y la pelea, el amor y la guerra producen un movimiento opuesto al nomadismo, puesto que "re-territorializan" al viajero Lamb, el cual jamás abandonará territorio uruguayo.

La "re-territorialización", no obstante, no produce formas de legibilidad o mapeo. En este sentido, Javier Uriarte, siguiendo a James C. Scott, argumenta que el espacio descrito por Lamb no se codifica de acuerdo a mapas estatales de legibilidad, sino que hay un paulatino alejamiento hacia zonas de invisibilidad de la mirada modernizadora (Uriarte 148). La zona de guerra, descrita sin estadísticas ni topografías específicas, no es un espacio productivo o susceptible de ser racionalizado, en una palabra, no es una zona apropiada para el business del imperio informal, en este caso la Inglaterra de la que es oriundo Lamb. Para Uriarte, la violencia que experimenta el personaje en su contacto con los gauchos provoca un tránsito de un locus ideológico imperial hacia zonas más complejas y menos mapeables (142). De acuerdo con esta lectura, agregaría que la invisibilidad productiva del mapa del territorio uruguayo se da no sólo por la experiencia de la violencia y la guerra, sino también por las aventuras amorosas en las que Lamb se involucra, las que crean mapas alternativos, que podrían

Revista Iberoamericana, Vol. LXXXII, Núm. 257, Octubre-Diciembre 2016, 703-719 ISSN 0034-9631 (Impreso) ISSN 2154-4794 (Electrónico) 
ser llamados mapas eróticos, como los del viajero y traductor Richard Burton en su Plain and Literary Translation of the Arabina Nights' Entertainment or the Book of Thousand Nights and A Night:

The map is open and connected in all of its dimensions; it is detachable, reversible, susceptible to constant modification. It can be torn, reversed, adapted to any kind of mounting, reworked by individual, groups or social formation. (Deleuze y Guattari, Thousand Plateaus 12) ${ }^{3}$

El lector recuerda a Montevideo por Paquita, al distrito de la Florida por Margarita, a Las Cuevas, por la mujer del juez, las orillas del río Yí, por Mónica y Alma, las inmediaciones de El Molino, por Dolores, a Candelaria cerca de Lomas de Rocha, etc. Al contrario de estereotipos en cuanto a la representación permisiva de la sexualidad de los nativos en los relatos de viajes y la descripción pormenorizada y desagradable de las características físicas y las prácticas incivilizadas de la Otredad (Eastman 13547), el viajero Lamb revela otras formas de experimentación del territorio a través del intercambio erótico con múltiples mujeres, las que marcan hitos en el mapa geográfico y afectivo de The Purple Land.

“Yo habríA HECHO IGUALES A TODAS LAS MUJERES". El DANDY ENAMORADO

Resulta sospechosa la no indagación de la crítica sobre los enamoramientos de Lucio V. Mansilla en Una excursión a los indios ranqueles. Mansilla se construye en cada capítulo como un sujeto melodramático, aventurero, con una preocupación extrema por la apariencia física, la moda y el flirteo, es decir como un dandy. Me parece interesante reparar en las veces que Mansilla habla de las mujeres y en especial de una mujer, su comadre mestiza/ranquel Carmen, por la que el narrador parece tener sentimientos que exceden el decoro de la sociedad argentina de fines de siglo, al menos en lo que refiere a la literatura de la elite y del gobierno.

Una excursión a los indios ranqueles es un libro de viajes de aventuras y tratado

Estudiando la traducción de Burton, Plain and Literary Translation of the Arabina Nights'Entertainment or the Book of Thousand Nights and A Night, especialmente su incorporación de notas al pie y su "Terminal Essay", Richard Phillips rescata esta definición más porosa de la construcción del mapa, de acuerdo a Deleuze y Guattari, y que es en definitiva la que le sirve al viajero orientalista Burton para situar la "Sotadic Zone" o zona de la pederastia (que en el siglo XIX se entendía sólo con hombres más jóvenes y no con niños), en la Europa mediterránea, el norte de África, Asia Menor y que se extendería hasta los límites con China y Japón. Se trata de una construcción del mapa que superpone sexualidad y geografía, con latitudes y longitudes bastante precisas. Para Phillips, si bien es cierto, puede hacerse una lectura orientalista del relato de Burton, la visibilidad tangible que su mapa sexual otorga a la homosexualidad estaba destinada a sacudir y criticar los prejuicios homofóbicos de la moral victoriana, cuya censura el libro de Burton tuvo que sortear.

Revista Iberoamericana, Vol. LXXXII, Núm. 257, Octubre-Diciembre 2016, 703-719 ISSN 0034-9631 (Impreso)

ISSN 2154-4794 (Electrónico) 
etnográfico con fuertes visos de melodrama y folletín. Como se sabe, en 1870, Lucio V. Mansilla (1831-1913), militar e intelectual de la élite argentina y sobrino de Juan Manuel de Rosas, partió a zona ranquel para confirmar un tratado de paz que él, a instancias del gobierno de Domingo Faustino Sarmiento, había iniciado con los indios dos años antes. El tratado era endeble y había sufrido ajustes y modificaciones de superiores a Mansilla, y éste quería con su viaje ratificar su palabra con los indígenas y demostrarle a Mariano Rosas, cacique ranquel, la buena fe que debía tener sobre lo acordado. La expedición de una escolta reducida partió el 30 de marzo de 1870 y duró dieciocho días, hasta el 17 de abril, en el transcurso de los cuales, Mansilla envió cartas a su amigo Santiago Arcos, interlocutor experto en la materia por ser autor de La cuestión de los indios. Las fronteras y los indios (1860). Dos meses más tarde, las cartas de Mansilla empezaron a ser publicadas en el diario La tribuna de Buenos Aires, revelando la intención pública de su escritura. El mismo año, a instancias de Héctor Varela se publica el libro en dos tomos. La edición autorizada aparecerá en 1877, editada en Leipzig, por F. A. Brockhaus (Sosnowski).

El libro de Mansilla surge en el seno de los debates sobre el progreso y la modernidad en Argentina, poniendo en tensión cuestiones que diez años más tarde encontrarán solución funesta con el genocidio de las poblaciones pampeanas y patagónicas en la Campaña del Desierto de Julio A. Roca (1880). Una excursión a los indios ranqueles habla de los malones y los cautivos, de los conflictos bélicos y políticos de una zona de frontera con fluidez de cuerpos, lenguas y mercancías. Se describe una zona permeable y bidireccional del contacto entre indios y cristianos. El tratado de paz de Mansilla propone ambiguamente la consolidación de un intercambio pacífico y regulado para que el progreso nacional expanda los límites territoriales. Mariano Rosas y los demás caciques desconfían, saben, justamente por el flujo no oficial de información, que los viajeros y cautivos proveen en la frontera, que este tratado quiere abrir las puertas a la creación del ferrocarril en zona ranquel, lo que llevará a la expulsión de los indios de su territorio hacia tierras patagónicas inhóspitas. Entre los muchos personajes y anécdotas, y la voz predominante de Mansilla como el eje articulador del relato, se hacen oír estas voces de desconfianza, presentadas en una luz crítica al proyecto modernizador del Estado. Mansilla consigna las tensiones propias y ajenas del discurso del progreso.

Mansilla crea un relato poroso, con grietas que permiten inscribir subjetividades alternativas como la de las mujeres indígenas y los sentimientos que ellas inspiran en el viajero nacional. Múltiples mujeres, esposas de caciques, novias de prófugos, indias y cautivas cristianas son representadas en el relato, sin embargo, la comadre Carmen sobresale entre todas ellas como una presencia indiscutida aunque fantasmagórica. Ella cumple el rol de mediadora asignado generalmente a las mujeres indígenas en situaciones de negociación política en zonas de frontera.

Florencia Roulet en "Mujeres, rehenes y secretarios" estudia el papel fundamental que los rehenes, las esposas y familiares de caciques jugaron en las negociaciones

Revista Iberoamericana, Vol. LXXXII, Núm. 257, Octubre-Diciembre 2016, 703-719 ISSN 0034-9631 (Impreso)

ISSN 2154-4794 (Electrónico) 
diplomáticas entre los enviados nacionales y los pueblos patagónicos y pampeanos. Lenguaraces, ex-cautivos, baqueanos, misioneros itinerantes, renegados, "aindiados", capitanes de amigos y jefes de frontera, estos personajes facilitaban la comunicación y el entendimiento entre las partes por el hecho de conocer tanto el mundo indígena como el hispanocriollo: "Entre pueblos que daban tanta importancia a la oratoria, fuente de prestigio y autoridad, y donde el procesamiento de un máximo de información constituía un 'fondo de poder' esencial para los caciques (Bechis 1999), hablar lenguas, ser 'ladino', realzaba la importancia del individuo" (304).

Las mujeres que negociaron tratados de paz, instruidas por sus parientes o por las autoridades españolas, parecen haber sido parte de un fenómeno bastante generalizado en los grupos étnicos del área pampeana y norpatagónica, por lo menos desde mediados del siglo XVIII hasta la ocupación militar en 1879. Estas embajadoras reunían importantes condiciones tales como: su parentesco con caciques, su manejo del castellano, sus contactos personales con hombres influyentes de la sociedad colonizadora, su parentesco simbólico con ellos (como el de ser sus comadres), capacidad de persuasión y observación. Roulet destaca que en la mayoría de los textos consultados, muchos de ellos relatos de viajeros, todas estas mujeres son nombradas como las "esposas de", "hermanas de", "hijas de", "madres de" caciques de cierta importancia, como la hermana del cacique tehuelche Bravo, de las sierras al sudoeste de Buenos Aires, gracias a la cual se firmaron las primeras paces en la frontera bonaerense, en 1742 . En la frontera mendocina, hermanas, esposas e hijas de caciques jugaron un papel crucial en el establecimiento de relaciones de alianza entre los pehuenches y los españoles. En 1780, como resultado de una expedición del comandante José Francisco de Amigorena contra las tolderías pehuenches del anciano cacique Guentenao en el cerro Campanario, los españoles regresaron a Mendoza con un grupo considerable de rehenes, entre las cuales se destacaron varias mujeres y principalmente María Josefa, hija del cacique Roco, quien se convertiría en el rehén más preciado por su papel como informante y diplomática (306). El estudio de Roulet revela así que el papel de las mujeres mediadoras y diplomáticas en la zona fronteriza fue fundamental en los encuentros militares y políticos aunque su voz haya quedado sumergida o "reducida" a una mera anécdota de la historia.

El fantasma de una mujer mediadora, Carmen, recorre el texto de Mansilla como una presencia salvadora o como un ángel guardián. ${ }^{4}$ En uno de los primeros encuentros con Mariano Rosas, el cacique quiere probar la resistencia y la camaradería de Mansilla invitándolo a sucesivas rondas de aguardiente. El resultado es, por supuesto, un Mansilla gravemente intoxicado que apenas puede sostener su cuerpo. En ese

4 En este sentido, habría que agregar a Carmen como actante substancial en la "novela de espionaje" que Fermín Rodríguez lee en Una excursión (Rodríguez 1996).

Revista Iberoamericana, Vol. LXXXII, Núm. 257, Octubre-Diciembre 2016, 703-719 ISSN 0034-9631 (Impreso) 
momento aparece una mujer en la oscuridad que lo rescata y su cuerpo se acerca al de Mansilla en íntima proximidad: "Mis piernas parecían dislocadas [...]. Haciendo un esfuerzo supremo, me enderecé. Describí dos semicírculos con los brazos. Hallé una mano pequeña, pulida, caliente, que me sostuvo, arrastrándome poco a poco. Un brazo rodeó mi cuerpo. Recliné mi cabeza desvanecida sobre un seno palpitante y di unos cuantos pasos [...]" (Mansilla 208).

Horas más tarde, Carmen confiesa ser la mujer que lo sostuvo. Y de nuevo impide que Mansilla y el negro acordeonista se peleen por un desacuerdo de autoridad, calmando al músico en araucano y a Mansilla en castellano, demostrando así sus indiscutidas virtudes como mediadora hasta en disputas cotidianas. A partir de este momento, el personaje de Carmen empieza a crecer sutilmente en el relato como indispensable a la excursión. En el momento más arduo de la negociación diplomática, cuando el archivo de Mariano Rosas es revelado a Mansilla como una acusación de la falsedad del tratado de paz, es decir Mariano acusa a Mansilla de traición y ocultamiento sobre las verdaderas intenciones del gobierno, Carmen reaparece como consuelo y como informante que pone en igualdad de condiciones a Mansilla y a Mariano Rosas en cuanto al conocimiento que los dos tienen de uno y otro lado. En el capítulo XL de Una excursión a los indios ranqueles, el cacique reprocha a Mansilla la planeación estatal del ferrocarril que atravesaría tierra ranquel, de la que se ha enterado a través de un recorte del diario La tribuna y que un cautivo ha traducido para él. El hecho es grave puesto que esta información en particular no se había hecho explícita en los discursos pronunciados por Mansilla en la negociación del tratado de paz, y la relación entre ambos líderes se tensa al punto de casi desmoronar todos los objetivos de la expedición. Mansilla describe el momento como "Noche de hielo. Donde realmente es triste la vida" (243). Hacia el final del capítulo los ánimos se levantan, cuando Carmen es llamada al fogón de los hombres de Mansilla y comienza su entretenido relato, del que no sabemos detalles sino hasta el capítulo siguiente. Notemos aquí el suspenso que genera la fragmentación de las entregas folletinescas o las cartas, formato original en el que Mansilla concibió el relato.

El capítulo siguiente es uno de los más etnográficos del libro y también uno de los más divertidos, tal vez por advertirse en él las virtudes de la conversación de Carmen. Al respecto resulta pertinente considerar la situación comunicativa del fogón, tan frecuentemente recreada en Mansilla, la literatura de viajes y la gauchesca. Samuel Monder analiza la circunstancia desjerarquizadora de las voces que se escuchan en el fogón, donde, en este caso, los soldados y el gauchaje adquieren preeminencia discursiva. El fogón, como versión telúrica del salón o del café, es anterior a la jerarquización del pacto social: "La disolución de jerarquías, la posibilidad de que el cocinero contradiga al oficial superior, supone jugar a bajar el telón sobre las obligaciones diurnas, y abrir el paréntesis en el que las ceremonias y el reglamento se suspenden momentáneamente

Revista Iberoamericana, Vol. LXXXII, Núm. 257, Octubre-Diciembre 2016, 703-719 ISSN 0034-9631 (Impreso)

ISSN 2154-4794 (Electrónico) 
[...]" (Monder 70). Es imprescindible situar en este contexto, las voces dialógicas de Carmen y Mansilla.

El capítulo se inicia con una ambivalencia pronominal, no se sabe claramente de quién se habla, si de Carmen o su hija (ahijada de Mansilla) sino hasta que se establece que Carmen es la informante sobre las creencias de los ranqueles:

Mi comadre Carmen vivía en Carrilobo, cerca del toldo de Villarreal, el casado con su hermana y había venido a visitarme trayéndome a mi ahijada.

Escuchándola, pasamos un rato muy entretenido. Habla con facilidad el castellano y posee bastante caudal de expresiones para manifestar sus sentimientos y hacerse entender. Sobre las creencias de los indios me dio las siguientes nociones: [...] (250; énfasis mío)

Esta manera de describir el relato de Carmen, como infantilizado, en un lenguaje suficientemente elocuente como para expresar sentimientos y "darse a entender" hace que se piense en un primer momento que se está hablando de una niña, la ahijada de Mansilla que ha venido trayendo Carmen de visita. Sin embargo, la última oración de la cita revela que es de la manera de contar de Carmen de lo que se está dando cuenta. En este sentido, el relato de Mansilla se adhiere a las convenciones en la representación de la voz del otro, típicas del relato de viaje, en donde el lenguaje y elocuencia de los interlocutores nativos aparecen exotizados y primitivizados, afirmando así la distancia y la superioridad del viajero, creando y reforzando los límites entre el yo civilizado y el otro colonizado.

En este marco de reproducción de voces jerarquizadas, no obstante, se da lugar a largos párrafos que transcriben la información que Carmen brinda, cuestionando los prejuicios del mismo Mansilla sobre las maneras de narrar de su comadre y reconstituyendo el performance de horizontalidad discursiva del fogón. Así, Carmen describe con detalle las creencias religiosas de los indígenas, la sabiduría contenida en el miedo y respeto al gualicho, porque éste:

[...] ocasiona los malones desgraciados, las invasiones de cristianos, las enfermedades y la muerte, todas las pestes y calamidades que afligen a la humanidad [...] [que está] en la fruta y en la yerba venenosa, en la punta de la lanza que mata; en el cañón de la pistola que intimida; [...] en el reloj que indica las horas, en la aguja de marear que marca el norte; en una palabra, en todo lo que es incomprensible y misterioso. (251)

El relato continúa en una suerte de estilo indirecto libre en el que se reproducen las marcas de la ágil fragmentación del relato oral y su co-presencia comunicativa, las que vuelven narración de una gran fluidez y entretenimiento al lector. La voz de Carmen se estiliza aquí asumiendo características metafóricas e imágenes poéticas. Se habla de la creencia en la vida después de la muerte, donde la voz de Mansilla incurre para explicar la creencia de los indígenas "[...] en la metempsicosis, como [la de] los

Revista Iberoamericana, Vol. LXXXII, Núm. 257, Octubre-Diciembre 2016, 703-719 ISSN 0034-9631 (Impreso)

ISSN 2154-4794 (Electrónico) 
hindúes, los egipcios y los pitagóricos" (251), del rol de las mujeres indias solteras, casadas, viudas y el de las cautivas en la sociedad ranquel, de la eufonía del araucano, su vocabulario, sus verbos y géneros gramaticales, y las elipsis de los sustantivos, con ejemplos adecuados y comprensibles para el lector no experimentado. Sin embargo, llega a saberse por el relato de Carmen, que el araucano es una lengua aprendida por ella en una socialización secundaria, dando a entender, sin establecer con claridad su origen, que Carmen no nació en la comunidad ranquel.

Carmen habla de la sexualidad de la mujer soltera, es decir de su propia sexualidad como mujer que no es casada ni viuda pero que tiene hijos, y "como la cosa más sencilla" refiere "sus aventuras con cierto mancebo", el padre de la ahijada de Mansilla. Se trata para Mansilla de "una página verde que en cualquier parte pasaría por una seducción. Entre los indios es un accidente de la vida que no significa nada. La especie humana está sujeta a la ley de la reproducción. Nada de extraño tiene que siendo mujer libre se entregue a quien le place, y que de la noche a la mañana resulte con hijos" (255).

El comentario de Mansilla revela la tendencia propia del discurso de los viajeros occidentales a naturalizar al Otro, principalmente el cuerpo de las mujeres en cuanto a la sexualidad y a la reproducción. Dicha naturalización adquiere aspectos de erotización de los que el imaginario burgués no puede liberarse, como se expresa en la frase "la página verde que en cualquier otra parte pasaría por seducción". Sin duda, esa "otra parte" es la sociedad de los lectores y la de Mansilla mismo. El relato de las libertades sexuales de Carmen no puede pasar desapercibido si se tienen en cuentan los sueños, pensamientos y reflexiones que Mansilla describe en las páginas subsiguientes y que tienen como tema central el amor y las mujeres, siempre en relación con los sentimientos que le inspira Carmen.

Esto se ve principalmente en los últimos capítulos, donde la despedida es inminente. En ellos, Carmen es descrita por Mansilla como alterada por la partida e intentando encontrarse a solas con él. Mansilla lee en la actitud y acciones de Carmen segundas intenciones que suscitan en el narrador una larga serie de reflexiones sobre la personalidad de las mujeres en el estilo del relato romántico decimonónico: infames, físicamente perfectas, espiritualmente monstruosas, hermosas como Niobe, dignas del amor de un dios olímpico, inconmovibles como rocas, frías como el hielo, olvidadizas como la mentira, buenas como la caridad, dulces como los querubines, puras como las auras del Elíseo, lindas y malas, de rostros angélicos y corazones satánicos, etc. (397-98).

En el medio de tales reflexiones, una frase intenta controlar el mundo heterogéneo que representan las mujeres para Mansilla, pero que también se puede leer como signo de su ansiedad racial ante el deseo sexual por una mujer no blanca: “¿Para qué completar el infierno de este mundo, había acaso necesidad de que las mujeres fueran demonios? Yo habría hecho iguales a todas las mujeres. ¿Las rosas no exhalan todas el mismo suavísimo perfume?" (398). En este frase Mansilla añora la clasificación ordenada del mundo y del deseo, una suerte de "territorialización" o codificación efectiva de los

Revista Iberoamericana, Vol. LXXXII, Núm. 257, Octubre-Diciembre 2016, 703-719 ISSN 0034-9631 (Impreso)

ISSN 2154-4794 (Electrónico) 
sentimientos. Sin duda, el que todas las mujeres fueran iguales ayudaría a mitigar la culpa que le ocasiona a Mansilla su deseo por Carmen.

Soy consciente que mi lectura es riesgosa, dado que Mansilla nunca hace explícito este deseo, algo por demás imposible si tenemos en cuenta las convenciones del relato de viajes de una figura pública y militar. Terminada la expedición, en un epílogo Mansilla establece el número total de población ranquel estimándolo de 8.000 a 10.000 indígenas, y los ubica en las coordenadas cartográficas de dos mil leguas cuadradas, entre los 63 grados de latitud sur y los 35 grados y 27 grados de longitud este, con los límites de la laguna del Cuero al norte, la punta del Río Salado al sur, el Río Salado al oeste y la pampa al este (432). Sin embargo, luego de las precisiones geográficas y demográficas con fines militares, a partir de las cuales el viajero visibiliza el territorio según el ojo del estado y el consumo económico de la tierra, Mansilla propone que la solución al problema de los ranqueles no es su exterminio sino su mezcla con los cristianos: "La conquista pacífica de los ranqueles, cuya fisonomía física y moral conocemos ya, para absorberlos y refundirlos, por decirlo así, en el molde criollo, ¿sería un bien o mal? En el día parece ser un punto fuera de disputa, que la fusión de las razas mejora las condiciones de la humanidad" (434).

Inserto en los debates biologicistas del darwinismo social, el alegato de Mansilla a favor del mestizaje puede ser interpretado no sólo a la luz de su conocimiento cercano de la sociedad ranquel sino también a partir del trato cotidiano con sus mujeres, como he analizado particularmente en el caso de Carmen. El salto de la experiencia individual al tono declaratorio y general del epílogo no debe confundirnos, en tanto sabemos que el deseo no es nunca individual sino más bien una construcción social y política. Deleuze y Guattari definen la sexualidad como "the libidinal unconscious of the political economy" (Young 168). El deseo se construye en una red de significados políticos y sociales, que en el caso del colonialismo resultan inseparables de la atracción y rechazo por la mezcla racial. Reconozco que se trata de una tesis arriesgada, como dije, pero no del todo improbable, en el que las relaciones sentimentales con las mujeres locales ejercen aquí, como en el caso de The Purple Land una fuerte influencia de re-territorialización.

En este sentido, el movimiento del viajero Mansilla describe bien los procesos de des-territorialización y re-territorialización del Estado argentino. Por un lado, la expansión de la modernidad y el capitalismo ejecuta acciones de violencia colonial desarticuladoras del espacio y sus habitantes originales, en este caso los ranqueles, obligándolos a la guerra, al éxodo y al exterminio. Por otro lado, agentes del Estado, burocráticos y diplomáticos, despliegan estrategias de re-territorialización, codificando de nuevo la demografía y reconfigurando geográfica y racialmente el mapa del territorio, a través del blanqueamiento del indígena por medio de una mezcla racial que "perfeccione" el fenotipo de la raza y sus cualidades morales. El reordenamiento (mestizaje) de los cuerpos de los indígenas hace que éstos se transformen en la mercancía legítima que dará lugar a la territorialización del proyecto de modernidad nacional.

Revista Iberoamericana, Vol. LXXXII, Núm. 257, Octubre-Diciembre 2016, 703-719 ISSN 0034-9631 (Impreso)

ISSN 2154-4794 (Electrónico) 
EL AMOR COMO TÁCTICA RE-TERRITORIALIZADORA

A modo de conclusión me gustaría resaltar la manera en que tanto el viajero inglés Lamb como el líder expedicionario argentino Mansilla codifican su relación con la nación y el imperio a partir de su pasión por las mujeres. Lamb con Dolores y Mansilla con Carmen proponen designios nacionales e imperiales contrarios a las políticas de sus respectivos países. En contra de una campaña militar aniquiladora, Mansilla parece redefinir la tensión entre la atracción y el rechazo por las indígenas por parte del sujeto nacional heterosexual -su lector- llegando a afirmar en el epílogo antes estudiado: “¿No tuvieron los conquistadores que casarse con mujeres indígenas, entroncando recién entre sí, pasada la primera generación? Y entonces, si es así, todos los americanos tenemos sangre de indio en las venas, ¿por qué ese grito constante de exterminio contra los bárbaros?" (434).

El lenguaje naturalista de Lamb, que Hudson bien conocía por ser él mismo un hombre de ciencias, es desmitificado y desautorizado en cuanto falsifica las tendencias eróticas del viajero imperial. Sus múltiples encuentros sexuales con mujeres uruguayas y argentinas, y principalmente el beso de Dolores, se presentan como los móviles de la conversión del inglés en gaucho. Es a través del amor que Lamb se vuelve un tránsfuga, en el sentido borgeano: aquel que abandona su cultura para abrazar la contrapuesta, como magistralmente lo plasmará Borges en historias como la de Juan Dalhmann en El Sur o en Historia del guerrero y la cautiva. Como he señalado en otras oportunidades, estos cuentos de Borges se inspiran en su lectura de viajeros ingleses. En The Purple Land, Lamb idealiza su viaje, haciendo referencia a la pérdida como colonia inglesa de la Banda Oriental:

No creo que si este país hubiese sido conquistado y vuelto a colonizar por los ingleses, $\mathrm{y}$ todas las cosas a nuestro juicio torcidas hubieran podido enderezarse, mis relaciones con las gentes del lugar habrían tenido el agreste y delicioso sabor que he gozado en ellas. Y si el sabor distintivo no puede ser logrado al par de la prosperidad material resultante de la energía anglosajona, quiero expresar mi deseo de que jamás esta tierra conozca la prosperidad. (286)

Con estos pensamientos, el relato de viaje de Lamb sitúa a Sudamérica en otro tipo de productividad imperial, no la del comercio y la explotación racional de la tierra, sino en la de la mercancía simbólica que constituye el paraíso perdido y la arcadia (erótica) en la literatura de viajes.

Revista Iberoamericana, Vol. LXXXII, Núm. 257, Octubre-Diciembre 2016, 703-719 ISSN 0034-9631 (Impreso)

ISSN 2154-4794 (Electrónico) 
BiBLIOGRAFíA

Burton, Richard. Plain and Literary Translation of the Arabian Nights 'Entertainmentor the Book of Thousand Nights and A Night. Benares: Kama-Shastra Society, 1885-6.

Deleuze, Gilles y Felix Guatari. Anti-Oedipus. Capitalism and Schizophrenia. Minneapolis: U of Minnesota P, 1972.

A Thousand Plateaus. London: Athlone, 1988.

Eastman, Carolyn. 'Beware of the Abandoned Women: European Travelers, 'Exceptional' Native Women, and Interracial Families in Early Modern Atlantic Travelogues." Atlantic Worlds in the Long Eighteenth Century: Seduction and Sentiment. Toni Bowers y Tita Chico, eds. New York: Palgrave Mcmillan, 2012. 135-47.

Gómez, Leila. Iluminados y tránsfugas: Relatos de viajeros y ficciones nacionales en Argentina, Paraguay y Perú. Madrid: Iberoamericana / Vervuert, 2009.

y Sara Castro-Klarén, eds. Entre Borges y Conrad. Estética y territorio en William Henry Hudson. Madrid: Iberoamericana / Vervuert, 2012.

Hudson, William Henry. La tierra purpúrea. 1885. Buenos Aires: El elefante blanco, 1999.

Mansilla, Lucio V. Una excursión a los indios ranqueles. 1870. Miami: Stockcero, 2007.

Monder, Samuel. "La ley del deseo: acerca de Una excursión a los indios ranqueles, de Lucio V. Mansilla". Iberoamericana 8/32 (2008): 61-74.

Phillips, Richard. "Writing Travel and Mapping Sexuality. Richard Burton's Sotadic Zone.” Writes of Passage. Reading Travel Writing. James Ducan y Gregory Decket, eds. London: Routledge, 1999. 70-91.

Pratt, Mary Louise. Imperial Eyes. Travel Writing and Transculturation. London: Routledge, 1992.

Rodríguez, Fermín. “Una excursión a los indios ranqueles. Una novela de espionaje”. Filología 29/1 (1996): 181-90.

Roulet, Florencia. "Mujeres, rehenes y secretarios: Mediadores indígenas en la frontera sur del Río de la Plata durante el período hispánico". Colonial Latin American Review 18/3 (December 2009): 303-37.

Said, Edward. Orientalism. London: Routledge \& Kegan Paul, 1978.

Sommer, Doris. Foundational Fictions: The National Romances of Latin America. Berkeley: U of California P, 1991.

Sosnowski, Saúl. Prólogo. Lucio Mansilla V. Una excursión a los indios ranqueles. Miami: Stockcero, 2007. XV-XXXIII.

Sparrman, Anders. A voyage to the Cape of Good Hope, and travels in the country of the Hottentots. Philadelphia: Printed and sold by Joseph \& James Crukshank, 1801.

Spurr, David. The Rhetoric of Empire: Colonial Discourse in Journalism, Travel Writing, and Imperial Administration. Durham: Duke UP, 1992.

Revista Iberoamericana, Vol. LXXXII, Núm. 257, Octubre-Diciembre 2016, 703-719 ISSN 0034-9631 (Impreso)

ISSN 2154-4794 (Electrónico) 
Uriarte, Javier. "Los espacios de la sangre: imperio informal, guerra y nomadismo en The Purple Land". Entre Borges y Conrad. Estética y territorio en William Henry Hudson. Leila Gómez y Sara Castro-Klarén, eds. Madrid: Iberoamericana / Vervuert, 2012. 129-55.

Young, Robert. Colonial Desire: Hybridity in Theory, Culture and Race. London: Routledge, 1995. 
